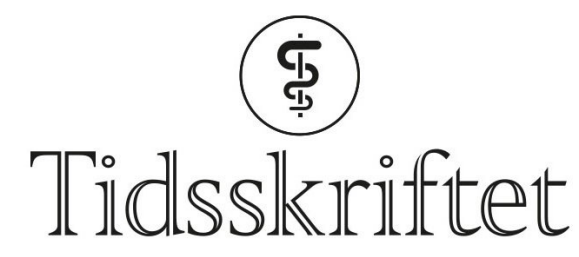

DEN NORSKE LEGEFORENING

\title{
Den alvorlige humorlegen
}

INTERVJU

CHARLOTTE LUNDE

E-post: charlottelunde@me.com

I komikermiljøet er Jonas Kinge Bergland «han legen». Blant leger er han blitt «han komikeren». Forvirret? Det er akkurat sånn han vil ha det.

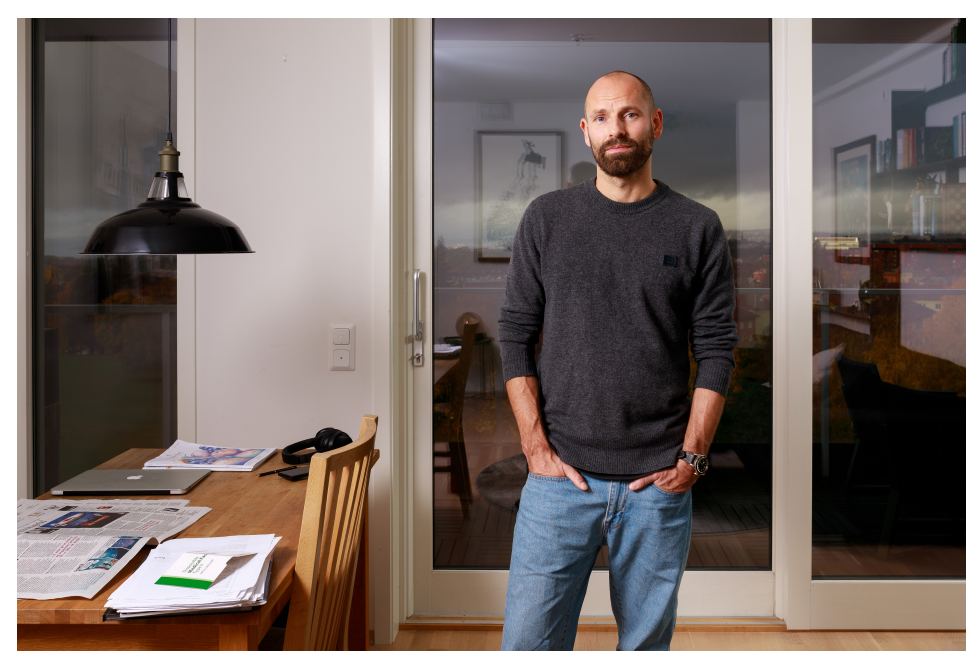

Foto: Niklas Lello

Mørkkledd og presis står han og ser på klokken idet vi ankommer. Vi er tre minutter for sent ute på avtalt sted, og forstår raskt at vi har å gjøre med en mann som skårer høyt på egenskapen planmessighet.

- Ja, det stemmer nok, innrømmer Jonas selvkritisk. Multitalentet Dr. Bergland, for de fleste kjent som komiker, men med en tidligere karriere som skiløper, karikaturtegner, skribent, podkaster, fastlege og nå sykehjemslege, legger snusboksen pent ved siden av kaffekoppen og legger en pris på plass.

- Jeg husker at jeg hadde gått femmila i NM med halvgodt resultat da en venn på kullet spurte: «Du, når skal du gi deg med den skikarrieren egentlig?» Det var en vekker. Jeg var kanskje god på ski, men jeg begynte for sent og holdt på for lenge, konstaterer Jonas, som om han avslører en karakterbrist. Så planmessig skal han ikke ha på seg at han er.

\section{Kontrollbehov}

På menyen hos Lorry velger Jonas klassisk egg og bacon, men til vanlig spiser han ikke hva som helst. Måltidsrutinene er kjent for å være sære. Frokost og lunsj er strenge ritualer.

- Det er alltid to skiver med blåbærsyltetøy og to glass melk til frokost. Først spiser jeg 
brødskive nummer en. Deretter drikker jeg glasset med melk. Alt i en slurk. Samme prosedyre gjentas med brødskive nummer to. Jeg blander aldri brød og melk. Det må være i riktig rekkefølge. Til lunsj er det to brødskiver med Jarlsberg-ost og en med krydderkremost, tomatskiver og sitronpepper. Jeg spiser alltid den med kremost som nummer to. Hver gang. Og jeg tar aldri telefonen når jeg spiser. Jeg kan egentlig ikke ha andre til stede når jeg kjører denne menyen. Da blir det rett og slett ikke like hyggelig, påpeker Jonas, og fortsetter uavbrutt:

- Etter at jeg har spist den første Jarlsberg-brødskiva legger jeg en iskaffe i fryseren. Når jeg har spist opp alle skivene, drikkes den nøyaktig så kald som den skal være. På PK (preklinisk institutt, red.anm.) hadde jeg en periode der jeg bare spiste egg. Jonas smiler. Detaljer om livet som komiker og lege må vi dra ut av han. Sin egen kostplan deler han med stor glede.

- Er du plaget av et kontrollbehov?

- Jeg må ha et system på det. He-he. Det høres galere ut enn jeg føler at det er, sier han og ler igjen.

Støland er en bra type. Korrekt og minst mulig emosjonell

Ellers ler han ikke så mye. Han liker å få andre til å le, men selv er han mer alvorlig enn forventet. På plakaten til standupshowet Dr. Bergland bryter taushetsplikten ser han til og med litt skummel ut. Som løytnant Støland i den populære NRK-serien Førstegangstjenesten fremstår han som autoritær, men sindig. Selv var han militærnekter, men rollen som militærleder liker han.

-Støland er en bra type. Korrekt og minst mulig emosjonell. Han lar deg ikke påvirke så mye, synes alt er litt kjedelig, men er grunnleggende ordentlig, summerer komikeren.

«Irriterende talentfull» er beskrivelsen en gammel kulling gir av Jonas, og med et snev av misunnelse legges det oppgitt til: «og nå har han begynt å spille gitar også ...».

En iherdig og pliktoppfyllende medisinstudent var han likevel aldri. Det koster å være komiker på kveldstid og studere medisin på dagtid.

\section{Jonas Kinge Bergland}

Født 1978

Embetseksamen i medisin, Universitetet i Oslo 2009

Klinikk for sex og samfunn 2011-13

Stensparken medisinske senter 2013-17

Langbølgen legesenter 2017-19

Madserud sykehjem 2019- d.d.

Komiprisen, Årets gjennombrudd 2012

Komiprisen, Årets standupkomiker 2017

- Jeg måtte ofte tegne foreleserne for å holde meg våken, forteller Jonas. Det ble etter hvert mange karikaturtegninger av medstudenter og fakultetets lærere. Ofte sovnet han. «Neppe har noen sovet så godt, og så mye på Riksen» står det i kullboka for Ho2 om Jonas Bergland. Kvelder og netter gikk med til standupshow, der han var oppvarmer blant annet for Bård Tufte Johansen og Thomas Giertsen. Etter forestilling satt han på bakrommet og leste pensum. En kveld han satt og slet seg gjennom pensum i obstetrikk og et kapittel om varigheten av et svangerskap, kommenterte Thomas Giertsen tørt:

«Hvorfor et helt kapittel om noe som består av to ord: ni måneder?»

Jonas knegger:

- Han hadde jo helt rett. 


\section{Gurustatus}

Etter hvert er det blitt større medisinske utfordringer fra profilerte standupkolleger. Gode kilder bekrefter at Jonas er blitt standup-Norges huslege etter at han diagnostiserte komiker Lisa Tønnes benigne hjernetumor på et nachspiel bak scenen en gang i 2012.

- He-he ... ja, det stemmer vel, drar han på det. Han ser nesten brydd ut. Historien må lirkes ut av han.

- Vel, Lisa fortalte at hun hadde nedsatt følelse på den ene siden av ansiktet. Da jeg undersøkte henne, hadde hun tydelige sensibilitetsutfall på venstre side tilsvarende andre gren av femte hjernenerve. Jeg ba henne sjekke seg. Det var alt, kommenterer han, og legger til:

- Jeg sa vel at en tumor ikke kunne utelukkes.

Lisa Tønne gjorde som hun ble anbefalt og fikk etter kort tid diagnostisert et akustikusnevrinom. Etter dette fikk Jonas gurustatus blant komikerkolleger. Det strømmer stadig på med ønsker om privatkonsultasjoner, der hypokondri og angst er hyppige tilstander, ifølge samme kilde. Jonas virker uberørt. Han foretrekker å holde sine fag adskilt.

- Det er to ulike verdener. Den ene skjønner ikke noe av den andre, selv om de to miljøene nok kan være litt nysgjerrige på hverandre. Men strengt tatt: Det er egentlig litt kjedelig å snakke om legeting til komikere, og omvendt, det er kjedelig å snakke om komikerting til leger. Så det gjør jeg ikke så mye.

\section{To roller som aldri bør møtes}

Han liker at folk er litt forvirret på hva han «egentlig» jobber med. Dobbeltkarrierer til tross: han er nøye med å ikke blande roller. Pasienter eller kolleger som møter Bergland på jobb som lege kan derfor bare glemme å få en vits servert. I legejobben passer han godt på å ikke være morsom. 


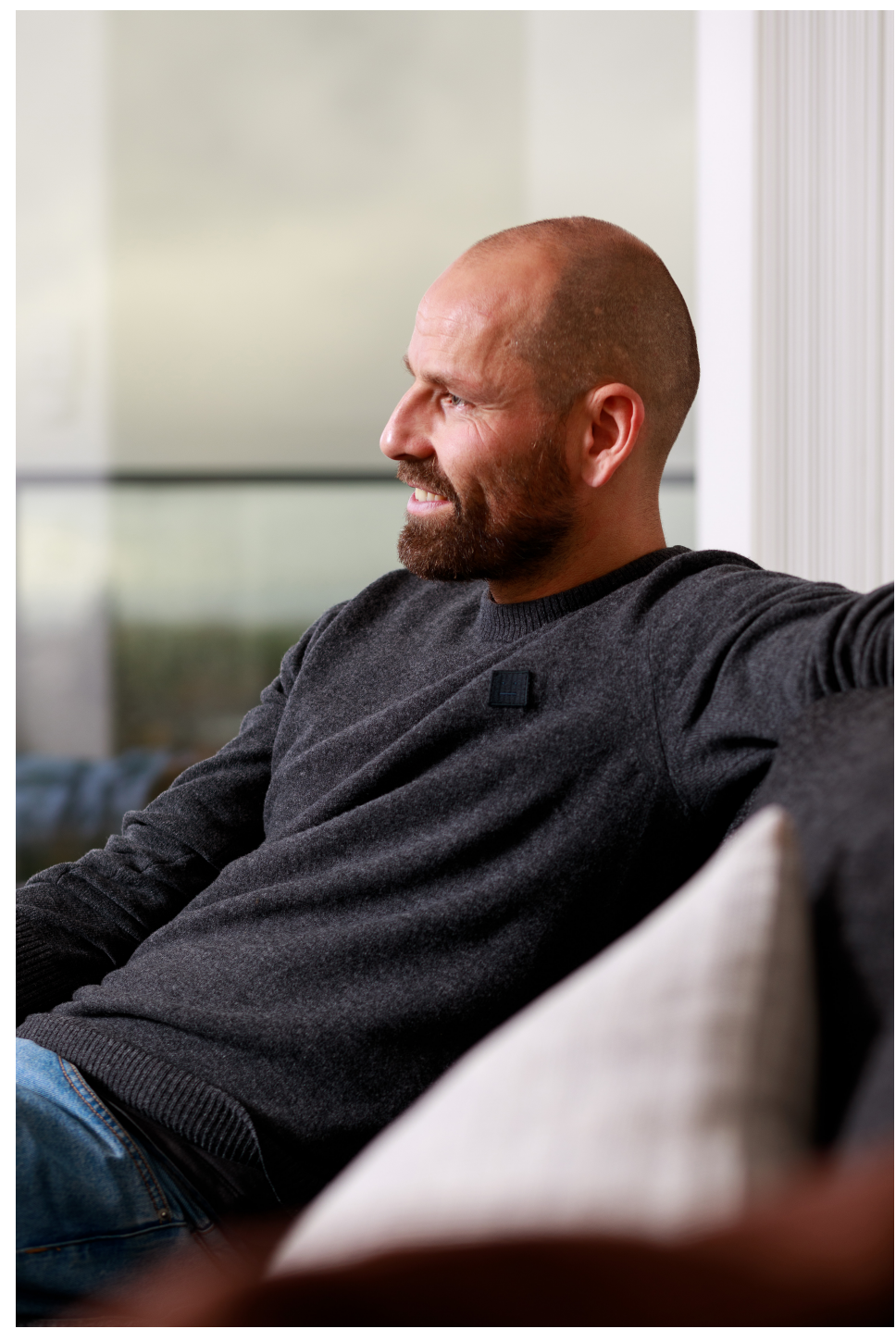

Foto: Niklas Lello

- Jeg tuller aldri med pasienter, sier Bergland med trykk på «aldri».

Han husker enda rådet han fikk av en kulling på studiet da han var i starten av karrieren som standupkomiker.

Jeg måtte ofte tegne foreleserne for å holde meg våken

- Jeg husker han så på meg lenge. Så sa han: «Komiker og lege, ja ... de to rollene må aldri møtes!». Jeg skjønner jo hva han mener. Jeg bruker legeyrket som komiker, men bare min egen rolle, sier Jonas. Etter syv år i allmennpraksis på Bislett jobber han nå som sykehjemslege på deltid, og er veldig fornøyd.

- Sykehjemsmedisin er helt topp. Du kan ta deg god tid, og så er det ekstremt spennende medisinsk. Jeg hadde ingen interesse av å drive butikk, slik du må i allmennmedisin. Du må stadig argumentere med pasientene for valgene du gjør. Vil noen ha en MR-undersøkelse når du mener det egentlig ikke er indikasjon, må du forhandle og jobbe hardt for å overbevise pasienten. På sykehjem er det en helt annen ro i prosessene. Det er lærerikt, sykehistoriene er sammensatt, og det er mye utfordrende pårørendearbeid.

Han har ingen hast med å gjøre medisinsk karriere og bli ferdig spesialist.

- Det tar nok lang tid før jeg får en pen CV i medisinfaget. Jeg har lyst til å bli flink til å jobbe med mennesker, og det å føle at du mestrer faget er enormt tilfredsstillende, men jeg er ikke spesielt ambisiøs karrieremessig akkurat nå. Jeg driver med mye annet. Da er fleksibilitet viktig. 


\section{Frosk og fjær}

Han er tredje generasjons oslogutt, men hadde en ganske utypisk urban oppvekst. På en gård midt på Holmlia med hest, gris, høns, gjess - og etter hvert påfugl - var ikke familien Kinge/Bergland den mest anonyme familien i nabolaget. Her startet også femåringen Jonas sin aller første nisjeinteresse mens familien hesjet høy, en heller ikke spesielt vanlig aktivitet i Oslo i 1980-årene:

- I dette halvtørka gresset var det ofte frosk, og jeg husker en gang en voksen sa «oj, en frosk!». Det fanget raskt interessen, og det ble som et lite eventyr hver gang det dukket opp en frosk, husker Bergland, som også forteller at han var mye alene i barndommen.

Nerdefaktoren var høy. Etter hvert ble det eget terrarium og en god venn som dyrket samme interesse.

Det er egentlig litt kjedelig å snakke om legeting til komikere, og omvendt, det er kjedelig å snakke om komikerting til leger

- Han flyttet dessverre tidlig, men vi fortsatte å holde kontakten gjennom brev. Jeg har de brevene hjemme og har lest dem i ettertid, sier han. Tema for brevutvekslingen til de to kameratene var ikke helt det man kanskje tror to femteklassinger ville ha vært opptatt av.

- Vi åpnet ikke brevene våre med «Hvordan går det?» eller «Har du truffet noen jenter siden sist?». Nei, vi gikk rett på sak: «Har du sett noe frosk?»

- I sin helhet handlet brevene om det vi samlet på: frosk, fjær og planter, oppsummerer Bergland.

\section{«En psycho familie»}

En liten periode drev også familien med fasanoppdrett, etter sterkt påtrykk fra familiens frosk og fjær-samler. Familien er i det hele tatt stadig svært viktig for legen og komikeren. Søndagsmiddagen er alltid hjemme på gården hos moren og faren. Foreldrene har jobbet som gårdbrukere og ungdomsarbeidere hele livet, og debatt med høy temperatur betyr god stemning.

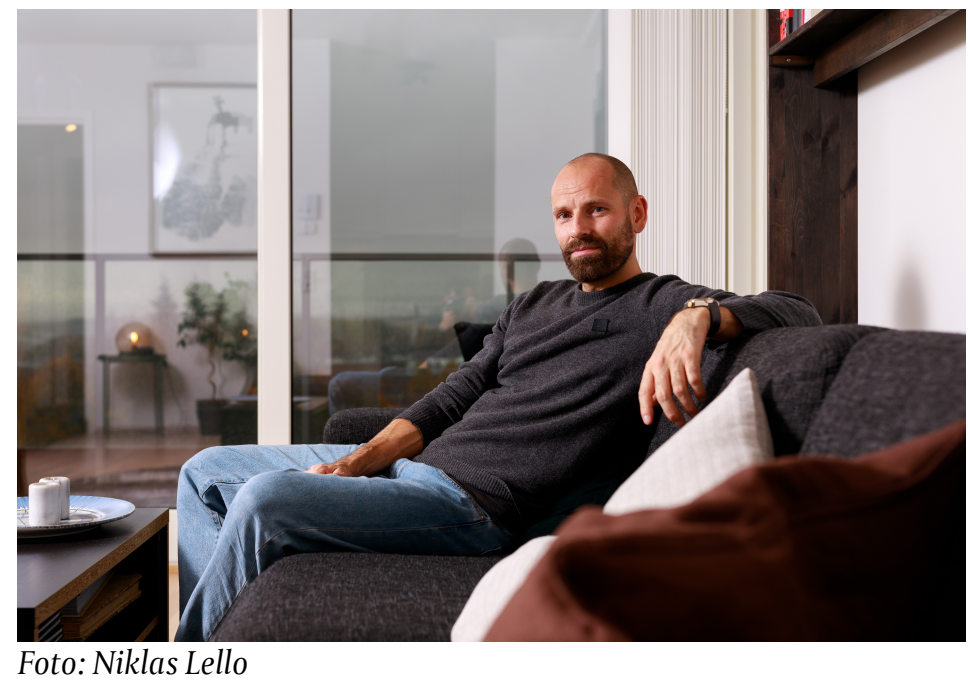

- Pappa er for tiden rasende på vindkraft, forteller Jonas og smiler.

- Jeg hadde med en kjæreste hjem en gang som ble vitne til den høye temperaturen i diskusjonene vi hadde rundt middagsbordet. Hun utbrøt etterpå: «For en psycho familie du har!» Hun var helt sjokkert over at det gikk an å ha så høylytt og hissig diskusjon der alle var enige, forteller 42-åringen. For Jonas er foreldrene et forbilde.

- Pappa er en kunnskapsrik, rasjonell og reflektert fyr uten angster. Hvis jeg blir lik pappa, er jeg grisefornøyd, sier komikeren og innrømmer samtidig at han ikke har samme ukompliserte personlighet. Den største helten er likevel morfaren. Som motstandsmann 
satt han i konsentrasjonsleir under krigen, og historiene fra Sachsenhausen er blitt en del av Kinge/Berglands familiemytologi.

- Morfar satt på brakke med Einar Gerhardsen og Arnulf Øverland, og det ble det mange historier av. Han fortalte masse om opplevelsen derfra da vi var små, men ikke på en tragisk måte. Morfar var utrolig morsom og fortalte om hvordan de underholdt hverandre i leiren med sketsjer og diktopplesning. Da en tysker senere en gang spurte om hvorfor han snakket så godt tysk, svarte han: «Jo, jeg hadde tysk på skolen da jeg vokste opp, og så hadde jeg et opphold i Tyskland senere, for å friske opp tysken.»

\section{Manus om anus}

I 2018 kom boka Manus om anus - kroppens (kanskje) viktigste organ som han skrev sammen med Kaveh Rashidi, og noen år drev han også podkasten Hva er greia med, der han sammen med en kulling og kollega forklarte fenomener om alt fra svartedauden til Ayn Rand.

- Det var gøy å drive podkast, men researchen tok etter hvert så lang tid at vi ikke hadde tid til å jobbe. Så den måtte vi legge ned, humrer Bergland.

Jobben som komiker har også brakt han til kjendisversjonen av $71^{\circ}$ Nord i 2016.

Realityserien der deltagerne beveger seg med stadig større fysiske utfordringer fra

Lindesnes til Nordkapp, brakte Jonas til finalen i konkurranse mot skihopper Anders

Jacobsen. Hans egne ambisjoner om å bli toppidrettsutøver hadde likevel blitt byttet ut med medisin da han forsto at hodet trengte en annen form for trening.

Sykehjemsmedisin er helt topp. Du kan ta deg god tid, og så er det ekstremt spennende medisinsk

- Jeg liker det målbare. Det var også derfor jeg begynte på medisin, slår han fast. Deltagelsen i $71^{\circ}$ Nord, hvor han ble slått på målstreken, bekrefter inntrykket av at Jonas Bergland har et rimelig sterkt konkurranseinstinkt.

- Jeg har alltid valgt å gjøre ting der prestasjonen kan måles på en slags skala. I langrenn er det plasseringen din på en resultatliste. Som standupkomiker er lattervolumet mål på hvor god du er på scenen. I medisinen handler det også om hva du kan, og hva du får til, sier han.

- Hvorfor er det sånn for deg?

Svaret kommer uten betenkning:

- Jeg innser at jeg har en tendens til å oppsøke situasjoner der jeg blir vurdert.

Denne høsten bekrefter seertallene at Førstegangstjenesten er en definitiv suksess. I likhet med løytnant Støland lar ikke Dr. Bergland seg rive med av det: "Jeg har ikke merka så mye til det egentlig». I underholdningsbransjen er han fortsatt «han legen».

- Jeg er nok er rart dyr uansett hvilket miljø jeg er i, sier Jonas - og ser ut til og trives godt med det.

Publisert: 19. november 2020. Tidsskr Nor Legeforen. DOI: 10.4045/tidsskr.20.0820

(C) Tidsskrift for Den norske legeforening 2020. Lastet ned fra tidsskriftet.no 